\title{
Grade Inflation: Too Much Talk, Too Little Action
}

Judson C. Faurer, Metropolitan State College of Denver, USA

Larry Lopez, Metropolitan State College of Denver, USA

\begin{abstract}
Grade inflation in academic institutions. Is it a subject so complex and pervasive in education that it defies resolution? The issue of grade inflation is of concern to college students, faculty, administrators and future employers. There is much gnashing of teeth, some veiled threats, wringing of hands, and both written and oral discussion of the topic but grade inflation persists. A few colleges have attempted to curb grade inflation through various grading policies that are often rejected by faculty and unfair to students. If the problem is generally universal among academic institutions and a threat to the validity of grades as an indicator of true academic performance, then why not establish grading guidelines, monitor adherence to the guidelines, and quit making such a fuss over grading? The purpose of this paper is to bring attention to the various questions that bear on the discussion, should be addressed in working toward a solution that may still be too elusive or contentious, and suggest actions to curb grade inflation.
\end{abstract}

\section{INTRODUCTION}

rade inflation in academic institutions - is it a subject so pervasive in education and so complex that it defies resolution and will continue to be a subject for debate and skepticism by all involved in or affected by the outcome? Who wants to bite the bullet for equitable grading? Students? Faculty? Administrators? Employers? There is much gnashing of teeth, some veiled threats, wringing of hands, and both written and verbal discussion of the topic but grade inflation persists. There is a proliferation of articles written by learned scholars and academic researchers about the problem, its causes and effects on individuals, institutions and curriculum. Many talk about the issue, plead or direct that more attention be paid to it but few institute specific actions to bring the grading in line with what is desired as a valid outcome of assessment. Those colleges/universities that have attempted to curb grade inflation through various grading policies often find the proscribed policies rejected by the faculty or termed unfair by students.

\section{WHO IS AFFECTED?}

\section{Students}

Some are affected more than others. There is no denying the intellectual superiority of the top percentage of students. Their accomplishments, skills, and scholarly attributes are unquestioned and even the envy of some of their professors. They are the far right of the normal bell curve. what is causing so much consternation is the vast group in the center of the learning distribution - those who might like to be as endowed as the gifted, think that hard work alone is the criteria for top grades or recognize the need to achieve top grades to be able to run with the pack in a competitive world and won't look in a mirror to acknowledge the person they see is a person who probability fits in well in many facets of society but is blessed with other attributes for success which may not be scholastic in nature. Does the persistence of grade inflation cause students to have a false sense of their self-esteem? If grade inflation is common knowledge among students, does the existing grade pattern cheapen the value and importance of both a college degree and academic honors resulting in less motivation on the part of the student to excel? (Schiming, 2005) 


\section{Faculty}

Many instructors would agree that grading is one of the most difficult aspects of teaching not only because of the time requirements but also due to the stress associated with making judgments about a student's performance in a course. Both of these factors may contribute to the problem of grade inflation. Add to this the link to student evaluations of faculty and the administration's review of the end-of-course evaluations in determining promotion, tenure, and merit pay and personal survival may outweigh objective grading.

\section{Institutions}

How long will an academic institution survive without enrollment and how is enrollment tied to institutional academic integrity? Degree mills will continue to exist and produce revenue so long as little attention is paid by potential employers to employees' sources of education but accredited schools must balance academic rigor and grading with prospective students' judgment of successfully achieving a degree with transcripts that support job opportunities ( Pilke, 2004).

\section{Employers}

Like it or not, many prospective employers still gravitate to the college transcript (and school's name) in making hiring decisions. Multiple interviews, various forms of testing, and recommendations are not fool proof assurances of a successful hire. Reliance on academic transcripts should be tell tale evidence that someone (a professor) carefully evaluated a student over many classroom hours and adjudged the individual to be worthy of the grade awarded and that the grade awarded was a true indicator of academic competence in the particular subject (course). With grade inflation there is the potential for hiring the unknown with concomitant turnover and loss of training dollars. Grade inflation has made grades and advancement difficult to rely on as a measure of success (Dresner, 2004).

\section{Consumers}

Degrees hung on the walls at doctors' officers or visibly displayed by many professionals attest to the sources of education. Consumers accept the academic degree as an indicator of academic competence at an acceptable level. Grade inflation can allow the best of mediocrity to surface in areas that can have significant and severe repercussions to the consuming public.

\section{WHY GRADE INFLATION PERSISTS}

It is easier to talk about grade inflation to demonstrate concern to all who are interested and involved than to take action that might offend some elements of the academic community. On politics most would favor a balanced budget as long as it does not impact negatively on their constituency. In academe, most support equitable grading as long as personal repercussions are avoided be it students, faculty, or institutions. Students are paying more for their education every year and increasingly they feel they should get the reward of a good grade for their purchase. This emergence of a consumer based culture in higher education has prompted professors to not only grade easier but to also water down course content (Rojstaczer, 2003). Not uncommon is the student lament "I worked hard in this course and deserve a corresponding grade". Hard work and demonstrated academic proficiency are not necessarily equated.

As long as there are links between grades and student evaluations of faculty, institutional needs for enrollment, non-standard grading criteria, student grade grievances, job tenure, and differences of perceptions of what is quality performance, grade inflation will persist.

Grading is a matter of perception, Just as beauty is in the eyes of the beholder, so is the assignment of grades subject to the values of the grader. The same people who were once on the receiving end of educational instruction and undoubtedly striving for grades as an indicator of their academic prowess (albeit over inflated ) are 
now on the giving end and tasked with evaluating the current crop of students. Has their attainment of a degree suddenly endowed them with the infinite wisdom to now judge others' performance? Were their grades inflated?

\section{SETTING THE STAGE FOR RESOLUTION}

Research, interviews, and observations all indicate that most faculty, departments, and schools within a college/university function autonomously within the academic community when it comes to grading. Even the national tests used to evaluate student knowledge cannot be relied on as a true indicator of proficiency in a subject because all subjects (courses) are not taught with a standardized syllabus, text, pedagogy, or outcome emphasis. Resultant grades are at best akin to a statistical confidence interval of actual content knowledge. There are those students who attain total mastery of a subject ( the far right under the bell grading curve ) and those who meet minimum standards for a passing grade (the far left under the bell curve).

But what are the standards against which grades are determined, are they universal, and is equitable (valid) grading achievable given the diversity of students, faculty, and institution demographics? The experiences of top tier students from high school enduring emotional stress when receiving average grades in academic institutions that try to invoke some degree of grading rigor are not uncommon. If the problem is generally universal among institutions of higher learning and a threat to the validity of grades as an indicator of true academic performance, then why not establish national grading guidelines, monitor adherence to the guidelines, and quit making such a fuss over grading? The model of education must change from one of information - transmission to an objective driven model (Brookhart, 1998).

SATs have been in existence for years and, in spite of some acknowledged faults, have been viewed as non-inflated or a true measure of scholastic aptitude upon which decisions such as admissions are made. There may not be a solution to grade inflation without acknowledging first whether there really is a problem considering that the factors bearing on the problem are too varied to allow any consensus on a solution.

\section{TOWARD A SOLUTION}

While there may be positive, practical, acceptable and feasible solutions to grade inflation, there are fundamental actions that should be taken to lay a groundwork for bringing grading in line. The suggested actions are not without some cost in time and money.

\section{Faculty training}

First, all entrants into the realm of professional instructors at the college level should attend a course in Academic Instructor Training by certified professional instructors who cover the myriad aspects of imparting and evaluating academic instruction. It will not standardize methodology to the $n$th degree but can significantly enhance conformity to proscribed standards.

\section{Categorize course pedagogy}

Although courses taught by varying pedagogies may be done to accommodate different learning styles and faculty preference, albeit with similar desired learning outcomes, the end results may be as different as basic research and applied research. In one class the basic essentials are taught and in another, perhaps an honors level course, the emphasis may be on exploring application or problem based learning. Is a grade under one approach equivalent to a grade under the other instructional method? Perhaps the grades should reflect the differentiation in instructional methods for the benefit of those reviewing transcripts.

\section{Eliminate grading in favor of Written General Reviews or comprehensive exams}

The true measure of education may be retention of what was learned beyond a semester or even the time spent achieving the final degree. If, philosophically, one seeks an education in order to apply the learning to life's journey then grades are strictly an ego trip along the way toward the attainment of the parchment. While it is 
impractical to use workplace performance as the criteria for awarding grades, a form of written general review at stages of degree attainment would be a more accurate measure of retained learning warranting the award of a degree which supposedly attests to one's knowledge. Comprehensive exams are a final testament to a potential graduate's knowledge would be almost irrefutable in evaluation of transcripts used in hiring.

\section{Administration support}

If grading is to left up to faculty (once properly trained and certified), then there must be support from the administration. The involvement of students in evaluating faculty through end-of-course critiques, while useful in some sense, when improperly weighed by administrators in annual faculty reviews results in faculty "playing to the audience" rather than enforcing academic rigor and standards. Frequent random peer/department chair reviews can provide the same degree of constructive feedback and probably with less incurred bias. Faculty should not be expected to serve two masters - students and administrators.

\section{Modified forced distribution}

If grade inflation is to be "brought under control" (whatever that may mean), then some stringent measures may be required. The use of rubrics and descriptions of what a letter grade should characterize about a student are helpful tools in the grade delineation process but they again leave it up to the faculty member to make a judgment in consonance with a descriptor. Establishing, for instance, that an "A" clearly indicates the student stands out as an excellent performer, has unusually sharp insight into material and initiates thoughtful questions, articulates well and writes logically and clearly, integrates ideas previously learned from current and other disciplines and anticipates next steps in progression of ideas, as opposed to a lesser descriptor for a "B" grade, could assist in a reasonable grade distribution. It might be that such an approach attacks the problem too close to the actual award of the grade when it would be better to start the grading differentiation in the formative stages of evaluating student performance, namely the type and use of instruments in evaluating performance. Assignments, exams, and observations that do not allow for ease of differentiation of results carry with them the seeds for grade inflation. Students complain when evaluative tools are "too tough" for all to master and, as mentioned earlier, castigate faculty in student end-ofcourse reviews. Assuming a well taught course, the measurement instrument needs to differentiate and in such a manner that students take responsibility for their scores, not faulting the instructor. Student communication, analysis, and critical thinking skills cannot improve without accurate, rigorous, and consistent evaluation of their work. Some schools direct that a certain grade point average be attained and not exceeded by a class when turning in grades. This means there needs to be methods to differentiate grading. A mandated mean of 2.6 on a 3.0 basis will force some lower grades to offset the higher ones and require differentiation. Other schools track faculty's grade point average over time as well as the variance from the average as a means of encouraging (intimidating) faculty to have a grade distribution. There are enough prospective faculty seeking teaching positions that those faculty who consistently fail to meet established GPAs or variances can easily be replaced especially in institutions that do not have tenure programs. Princeton, for instance, reviewed a proposal to limit the number of A's from 46 percent to 35 percent for undergraduate courses with each department expected to meet the limit on A's even though grades could vary by class $(\mathrm{CNN}, 2004)$.

\section{Grouping students by ability}

As a means of grouping like learners together (perhaps for their own benefit), students could be placed in classes by GPA or shuffled between various learning levels at intervals during a semester. This does two things in a subtle manner. Those who absorb faster are provided opportunity for accelerated learning beyond the course requirement and it sends a quiet message to the average learner that the concomitant grade in the course is commensurate with the learner's ability and takes the burden off the instructor. It also allows the instructor who so desires to interact with students who might contribute to research, creative teaching, or course enhancement.

\section{REACHING CONSENSUS}

It is highly doubtful that grade inflation will correct itself without a consensus of widespread, controversial actions. There will be initial discord until all (faculty students, and administrators) recognize the value of output 
(education) received under standards. In the absence of fair grading, [an institution] success in providing the nation with a truly educated public is diminished and the implications of such failure for a free society are tremendous (Rojstaczer, 2003).

\section{REFERENCES}

1. Brookhart, Susan, "Why Grade Inflation is Not a Problem With a 'Just Say No' Solution", National Forum, Spring 1998.

2. Dresner, Jonathan, "Grade inflation...Why It's a Nightmare”, August 2, 2004, http://hnn.us/articles/6591.

3. Mansfield, Harvey, "Grade Inflation: It's Time to Face the Facts", Chronicle of Higher Education, April 6, 2001.

4. Pielke, R, "Grade Inflation", Center for Science and Technology policy Research, University of Colorado at Boulder, April 23, 2004.

5. "Princeton weighs Plan to Curb Grade Inflation", CNN.com, April 8, 2004, http://www.cnn.com/2004/EDUCATION/04/08/princeton.

6. Rojstaczer, Stuart, "Grade Inflation at American Colleges and Universities", National Trends in grade Inflation, March 17, 2003, http://www.grade inflation.com.

7. Rojstaczer, Stuart. "Where All Grades are Above Average", Washington post, January 28, 2003.

8. Schiming, Richard, "Grade Inflation”, Center for Excellence in Teaching and Learning, Minnesota State University, 2004. 
NOTES 